\title{
SAG2A protein from Toxoplasma gondii interacts with both innate and adaptive immune compartments of infected hosts
}

\author{
Arlindo G Macêdo Junior' ${ }^{1}$ Jair P Cunha Junior ${ }^{1}$, Thyago HS Cardoso², Murilo V Silva', Fernanda M Santiago ${ }^{1}$, \\ João S Silva ${ }^{3}$, Carlos P Pirovani ${ }^{2}$, Deise AO Silva', José R Mineo ${ }^{1}$ and Tiago WP Mineo ${ }^{1 *}$
}

\begin{abstract}
Background: Toxoplasma gondii is an intracellular parasite that causes relevant clinical disease in humans and animals. Several studies have been performed in order to understand the interactions between proteins of the parasite and host cells. SAG2A is a $22 \mathrm{kDa}$ protein that is mainly found in the surface of tachyzoites. In the present work, our aim was to correlate the predicted three-dimensional structure of this protein with the immune system of infected hosts.

Methods: To accomplish our goals, we performed in silico analysis of the amino acid sequence of SAG2A, correlating the predictions with in vitro stimulation of antigen presenting cells and serological assays.

Results: Structure modeling predicts that SAG2A protein possesses an unfolded C-terminal end, which varies its conformation within distinct strain types of T. gondii. This structure within the protein shelters a known B-cell immunodominant epitope, which presents low identity with its closest phyllogenetically related protein, an orthologue predicted in Neospora caninum. In agreement with the in silico observations, sera of known T. gondii infected mice and goats recognized recombinant SAG2A, whereas no serological cross-reactivity was observed with samples from $N$. caninum animals. Additionally, the C-terminal end of the protein was able to down-modulate proinflammatory responses of activated macrophages and dendritic cells.
\end{abstract}

Conclusions: Altogether, we demonstrate herein that recombinant SAG2A protein from T. gondii is immunologically relevant in the host-parasite interface and may be targeted in therapeutic and diagnostic procedures designed against the infection.

Keywords: Toxoplasmosis, Protein modeling, SAG2A, Monoclonal antibodies, Recombinant protein

\section{Background}

Toxoplasmosis is a zoonosis caused by Toxoplasma gondii, a coccidium member of the phylum Apicomplexa. T. gondii is present in a wide range of vertebrate hosts, including humans, which normally present asymptomatic infections. However, severe diseases may be observed in immunocompromised individuals and in congenital infection $[1,2]$. According to seroepidemiological data, approximately one third of the world population is

\footnotetext{
* Correspondence: tiagomineo@icbim.ufu.br

'Laboratório de Imunoparasitologia "Dr. Mário Endsfeldz Camargo", Instituto de Ciências Biomédicas, Universidade Federal de Uberlândia, Av. Pará 1720 Bloco 4C, Campus Umuarama, Uberlândia, Minas Gerais 38.400-902, Brazil Full list of author information is available at the end of the article
}

chronically infected by the parasite, although prevalence may vary between $10 \%$ and to $80 \%$ depending on the economic, cultural and health status $[3,4]$.

Several studies have been performed in order to understand the interactions between the parasite and its host cells [1,5-7]. Among the different classes of studied molecules, special attention has been spent on the glycosylphosphatidylinositol (GPI)-anchored proteins named SAG (surface antigens), SRS (SAG1-related sequences) and SUSA (SAG-unrelated surface antigens). The SRS family is divided into two major branches: the SAG1-like sequence family (SAG1, SAG3, SRS1SRS4, BSR4) and the SAG2-like sequence family (SAG2ABCDXY) $[1,8]$.

\section{C) Biomed Central}


Genomic/Proteomic research within the T. gondii model has been very useful for the understanding of cell invasion mechanisms, cell cycle and immune evasion [9-12]. Protein modeling has been broadly used nowadays [13-15]. It is used to discover the spatial organization of a protein by prediction of molecular interactions, based on the crystal structure of relatively similar amino acid sequences, which may provide relevant data on its function and active sites. An example for the application of such techniques is the knowledge generated on the structural characterization of the Moving Junction (MJ), a complex structure produced by the parasite that is essential for host cell invasion $[14,16]$.

In this study, we aimed to evaluate the interplay between the predicted three-dimensional structure of SAG2A protein and the immune system of its hosts, as shown here for mice and goats. Taken together, our results suggest that surface SAG2A protein contains an active C-terminal region that interacts directly with innate and adaptive immune mechanisms.

\section{Methods}

\section{Ethics statement}

Maintenance and care of mice were performed according to The Ethical Principles in Animal Research adopted by the Brazilian College of Animal Experimentation (COBEA) and was approved by the Ethical Commission of Ethics in Animal Research of the School of Medicine of Ribeirão Preto, University of São Paulo (CETEA-FMRP/USP), under protocol number 059/2007.

\section{Reagents}

Reagents for cell culture were obtained from Life Technologies (Carlsbad, CA, USA) and Sigma-Aldrich (St. Louis, MO, USA); Reagents for detection of mouse IL-12p40 and TMB substrate were acquired from Becton and Dickinson (BD, San Diego, CA, USA). Lipopolyssacharide (LPS from Salmonella typhymurium), Griess reagent (sulfanimide and naphtylethylenediamine) and bicinchoninic acid (BCA) were acquired from Sigma-Aldrich (St. Louis, MO, USA). Recombinant cytokines GM-CSF, IL-4 and IFN- $\gamma$ were acquired from Peprotech (Rocky Hill, NJ, USA). Monoclonal antibodies and irrelevant mouse IgG were purified using immobilized protein G-sepharose columns (Sigma). For protein concentration and ultrafiltration we used the Amicon system (Millipore, Billerica, MA, USA). Antigens were preserved from degradation by the addition of a protease inhibitor cocktail (Complete, Roche Applied Science, Mannheim, Germany). Recombinant proteins were determined as endotoxin free by a modified Limulus amebocyte lysate assay (LAL, BioWhittaker, Walkersville, MD, USA).

\section{Mice}

Six- to eight-week old wild type (WT) C57BL/6 background mice were supplied by the Department of Biochemistry and Immunology, School of Medicine of Ribeirão Preto, USP, Ribeirão Preto, Brazil, and were bred and maintained at the institutions' animal facilities, with food and water ad libitum.

\section{Cell culture, parasites and antigens}

T. gondii (RH and Me49 strains) tachyzoites were maintained in HeLa cell lines (ATCC/CCL-2; American Type Culture Collection, Manassas, VA, USA) grown in RPMI 1640 medium supplemented with $2 \%$ fetal calf serum at $37^{\circ} \mathrm{C}$ in a $5 \% \mathrm{CO}_{2}$ air environment. Parasites were harvested by scraping off the cell monolayer 5 days after infection and were purified by forcible extrusion through a 27 -gauge needle and centrifugation $\left(45 \times \mathrm{g}, 1 \mathrm{~min}, 4^{\circ} \mathrm{C}\right.$ ) to remove host cell debris.

\section{Construction of plasmid, expression and purification of recombinant proteins}

T. gondii genomic DNA from RH strain tachyzoites was isolated as previously described [17], and the construction of plasmids, expression and purification of recombinant SAG2A (rSAG2A) and truncated protein at position 135 $\left(\mathrm{rSAG} 2 \mathrm{~A}^{\Delta 135}\right)$ were produced as described elsewhere [18]. Briefly, native SAG2A coding sequence was obtained in a public database (GenBank: AAO72427.1; [19]). Signal peptide and predicted GPI anchor were removed, and the template used for protein expression comprised of amino acids between 30 and 156 of the deposited sequence. For cloning and expression of the recombinant proteins, we used pET28a vector and E. coli Rosetta DE3 strain. To remove possible contamination from the process, protein purification was performed as previously described [20]. Briefly, Triton X-114 was added to purified SAG2A fraction to a final concentration of $1 \%$. The mixture was incubated at $4^{\circ} \mathrm{C}$ for $30 \mathrm{~min}$, with constant stirring to ensure a homogenous solution. The sample was then transferred to a $37^{\circ} \mathrm{C}$ water bath, incubated for $10 \mathrm{~min}$ and centrifuged $\left(13,000 \times g, 10 \mathrm{~min}, 25^{\circ} \mathrm{C}\right)$. The upper aqueous phase containing the protein was carefully removed and again subjected to Triton X-114 phase separation for at least two cycles. Additionally, the aqueous phase containing the protein was loaded into a Sephadex G75 column $(1 \times 50 \mathrm{~cm})$ that had been previously equilibrated with $10 \mathrm{mM}$ Tris- $\mathrm{HCl} \mathrm{pH} 7.4$ containing $0.5 \mathrm{M} \mathrm{NaCl}$. The chromatography was performed with a flow rate of $3.5 \mathrm{ml} / \mathrm{min}$ and $500 \mu \mathrm{l}$ fractions were collected and monitored at $280 \mathrm{~nm}$ OD. The fractions with high absorbance values were analyzed by SDS-PAGE, and the corresponding fractions were combined and concentrated by ultrafiltration. After purification, the protein concentration was determined by 
BCA method and screened for the presence of endotoxins by LAL assay.

\section{Protein modeling}

To construct three-dimensional structures of SAG2A, modeling was based on structures solved by X-ray crystallography or RMN using the algorithm blastp and PSI-Blast (www.ncbi.nlm.nih.gov/BLAST) [21], using the matrix of alignment Blossum62 [22]. Sequences of the desired proteins were obtained at Protein database from the National Center for Biotechnology Information (NCBI, www.ncbi.nlm.nih.gov/protein) and at The Toxoplasma Genome Resource (ToxoDB, www.toxodb.org). The search for patterns was configured to use only the PDB database (www.pdb.org), which owns all three-dimensional structures of proteins from data of X-ray crystallography or NMR already published. For the construction of the models, we considered only those with identity above $25 \%$ and E-values of less then e.10 $0^{-5}$. The verification of motif sequences belonging to the active site of molecules, such as protein family, was also taken into consideration in the choice of templates. The template chosen for the construction of three-dimensional models of $T$. gondii proteins SAG2A, as well as SAG2A orthologue from $N$. caninum (NcSAG2A; ToxoDB: NCLIV_035760), was the crystal structure of SAG1 (PDB: 1KZQ; [23]), which presents the conserved SAG superfamily motif and presented at least $35 \%$ identity with the modeled proteins. Construction of SAG2A three-dimensional model followed the sequence used for recombinant protein synthesis. The three-dimensional structure for BSR4 protein was analyzed according to its deposited crystal structure (PDB: 2JKS; [24]).

The initial structures obtained by homology modeling, were submitted to the validation process, using the programs PROCHECK 3.4 [25] and ANOLEA (Atomic Non-Local Environment Assessment) [26,27]. Validation by PROCHECK allowed the verification of stereochemical quality of the modeled structures, comparing them with other well refined structures at a resolution of $2.0 \AA$, as well as the residue to residue analysis of these structures. In this analysis, Ramachandran graphics [28] and other plots were generated for the validation of the three dimensional structure, plotting angles and torsion of chi1 and chi2 for all residues, planarity of peptide bonds, poor interaction between unconnected atoms, binding strength of hydrogen in the main chain and side chain properties [25]. Through validation by the ANOLEA, provided by Swiss-Model server (swissmodel.expasy.org/anolea), the total energy values of the models of the SAG2A proteins were calculated. This software evaluated the non-local environment of each heavy atom of these molecules. The interaction energy of each pair of atoms in their non-local environment was calculated using the potential strength dependent on the distance, within a radius of $7 \AA$ for each amino acid, which was compared with a database of 147 non-redundant protein chains, with a sequence identity above $25 \%$ and obtained from X-ray crystallography with a resolution below $3 \AA$ [27]. The GPI anchoring site of SAG2A was predicted using online tool PredGPI (http://gpcr.biocomp.unibo.it/predgpi).

\section{Bone marrow-derived macrophages and dendritic cells}

Bone marrow-derived macrophages (BMMs) were generated from bone marrow stem cells of C57BL/6 background mice, as previously described [29]. Briefly, stem cells were cultured on $10 \mathrm{~cm}$-diameter polystyrene plates for 7 days in RPMI 1640 medium containing HEPES $15 \mathrm{mM}, 2 \mathrm{~g}$ of sodium bicarbonate/liter, and $1 \mathrm{mM} \mathrm{L}$-glutamine and supplemented with $20 \%$ heat-inactivated fetal calf serum (FCS) and 30\% L929 cell conditioned medium (LCCM). Differentiated BMMs were removed from the substrate by vigorous pipetting of ice-cold phosphate-buffered saline. Cells were counted and added $\left(2 \times 10^{5}\right)$ to 96 -well culture plates for the experiments.

Bone marrow-derived dendritic cells (BMDCs) were generated as previously described [30]. Briefly, bone marrow stem cells were cultured $\left(7 \times 10^{5}\right.$ cells/well) in 24-well culture plates in RPMI medium supplemented with $10 \%$ CFS, $30 \mathrm{ng} / \mathrm{ml}$ of murine granulocyte-macrophage colony-stimulating factor (GM-CSF) and $10 \mathrm{ng} / \mathrm{ml}$ of murine recombinant IL-4. On days 3 and 6, supernatants were gently removed and replaced with the same volume of supplemented medium. On days 7-8, non-adherent cells were removed and plated on 96-well culture plates prior to stimulation.

\section{In vitro stimulation}

In all in vitro experiments, cells were cultured in 96-well culture plates, in quadruplicate, using incomplete RPMI medium in the presence of $T$. gondii $\mathrm{RH}$ or Me49 strain tachyzoites, at different parasite:cell ratios (multiplicity of infection - MOI) and concentrations of recombinant SAG2A proteins, specific monoclonal antibodies (A4D12; [18]), or medium alone (negative control) at $37^{\circ} \mathrm{C}$ and $5 \%$ $\mathrm{CO}_{2}$ for 24 hours. BMMs pre-incubated with antigens or live parasites were stimulated with LPS and IFN- $\gamma$ for further 48 hours, while BMDCs were stimulated with LPS for further 24 hours. After this period, the culture supernatants were removed for cytokine and nitric oxide measurements.

\section{Cytokine quantification by ELISA}

The concentrations of IL-12p40 in cell culture supernatants were measured by commercial kits, according to the manufacturer's instructions. Plates were read in a plate reader (Molecular Devices, Sunnyvale, CA, USA) at 
$450 \mathrm{~nm}$. Cytokine concentrations were calculated from standard curves of murine recombinant cytokines. The detection limits for the assay was $15.6 \mathrm{pg} / \mathrm{ml}$.

\section{Measurement of nitric oxide production}

Nitric oxide production was measured by nitrite concentration in supernatants obtained from stimulated BMMs and BMDCs cultures by Griess assay [31]. Briefly, Griess reagent (sulfanimide 1\% and naphtylethylenediamine $0.1 \%, 1: 1$ ) was added to the culture supernatants. Absorbance was measured at $540 \mathrm{~nm}$. NO concentration was determined using standard curve established with a $200 \mu \mathrm{M}$ sodium nitrite solution. The sensitivity limit was $1.563 \mu \mathrm{M}$.

\section{Immunoassays}

ELISA and Western blotting protocols using recombinant SAG2A (rSAG2A) were performed for the detection of IgG antibodies present in serum samples of experimentally infected mice and naturally infected goats to T. gondii and $N$. caninum, as previously described [32,33]. Antibody titers were expressed as ELISA index (EI), according to the following formula: EI = OD sample/OD cut off, as described elsewhere [34]. Samples with EI values $\geq 1.2$ were considered positive.

\section{Statistical analysis}

Two-way ANOVA followed by Bonferroni posttests were applied to compare groups in relation to NO, IL-12p40 production. In all measurements, differences were considered significant when $p<0.05$. All experiments were performed at least three times, and executed in different days. Statistical analysis of the data obtained was carried out using GraphPad Prism software (GraphPad, La Jolla, CA, USA).

\section{Results}

After performing the in silico analysis of the threedimensional model of SAG2A and known crystal structures (SAG1 and BSR4), we observed that the single domain of SAG2A protein presents a predicted disordered amino acid sequence forming a prominent loop in its C-terminal end (Figure 1). Interestingly, this same conformation was not observed in the crystal structure of tachyzoite-related surface proteins SAG1 [23] and in bradyzoite-related BSR4 [24]. Both proteins present a more complex structure - composed of two distinct domains (external and internal domains; D1 and D2, respectively) - and are disposed as dumbbell shaped monomers. The unique domain of SAG2A presented higher similarity to D1 of the other SAG-related proteins (Figure 1).

Anchorage by glycosylphosphatidylinositol (GPI) in SAG2A was predicted in a leucin at position 169 of its amino acid sequence, within C-terminal region of SAG2A
(Figure 2A), in contrast with the anchorage of SAG1 and BSR4 proteins, which occurs in D2 domains [23]. The monomer is maintained by eight beta-sheets producing a structure similar to the internal domains of the other SRS members analyzed, although SAG2A presents a unique extended loop (Figure 2B). Concerning the polarity of SAG2A molecule, it could be observed that its three-dimensional structure did not present a predominance of charges in its surface. However, the loop region within the $\mathrm{C}$-terminal end displays a high hydrophobic portion with only two terminal polar amino acids, a positive and a negative residue (Figure $2 \mathrm{C}$ ).

Phylogenetic analysis of the SAG2A sequence revealed its resemblance to other members of the SAG2 cluster from $T$. gondii, although it presented higher identity with predicted orthologues from $N$. caninum (NcSAG2A), a closely related coccidian parasite (Figure 3A). Modeling of NcSAG2A suggested similar overall structure of the orthologues, although the models predicted for both proteins differed in the structural organization of the loop present at the C-terminal end of the molecules (Figure $3 \mathrm{~B}$ ). While SAG2A from $T$. gondii presents a largely disordered loop, NcSAG2A presents a loop sequence composed with beta-sheets.

SAG2A is a serologically immunodominant protein, mainly recognized in the acute phase of the infection by $T$. gondii [32]. Noteworthy, we have previously characterized a $B$ cell epitope (NDGSSA) in this protein using monoclonal antibodies (A4D12 mAb; [18]). In the present work, our results suggest that this immunodominant epitope is located within the C-terminal end of the amino acid sequence (purple highlight, Figure $3 \mathrm{~B}$ ). Overall, sequence alignment of the SAG2A orthologues resulted in a high percentage of identity and similarity between these proteins, although NcSAG2A differed significantly from $T$. gondii SAG2A in the described IUP domain (Figure 3C). In order to check if the lack of homology in the loop sequences of SAG2A orthologues could confer unique antibody responses, we assayed serum samples of infected animals from both parasites against recombinant T. gondii SAG2A protein (rSAG2A). IgG antibodies from mice reacted strongly with rSAG2A by ELISA, after 30, 60 and 90 days of experimental infection with $T$. gondii, while no reaction was observed in samples from mice infected with $N$. caninum (Figure 3D). The same serological specificity was observed by Western blotting analysis of samples obtained from naturally infected goats - a ruminant known to be clinically affected by both parasites [35]. As expected, only samples from animals infected with $T$. gondii recognized the $22 \mathrm{kDa}$ rSAG2A (Figure 3E).

$T$. gondii is known to actively interfere in macrophage functions, through the blockage of innumerous LPS-inducible cytokines, modulation of the host gene expression, inhibition of IL-12p40 and TNF- $\alpha$, and 


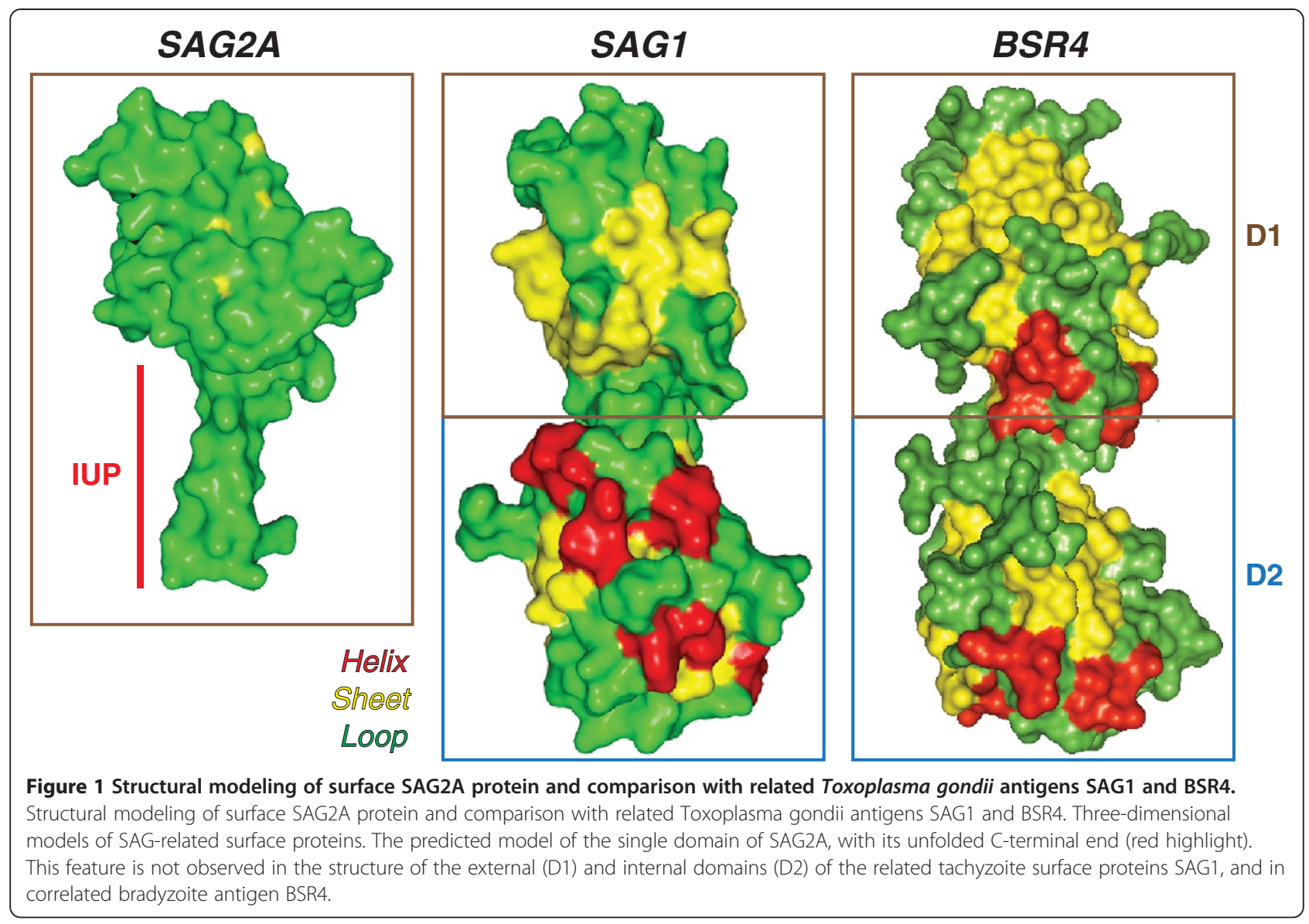

suppression of nitric oxide $(\mathrm{NO})$ production [36-38]. In that sense, we assessed whether SAG2A presented noted biological activities in innate immune cells. For that, we measured NO and IL-12 production in bone marrow derived macrophages (BMM) and dendritic cells (BMDC), exposed to rSAG2A, as well as a truncated protein lacking its C-terminal end (rSAG2A ${ }^{\Delta 135}$, Figure 4A). Treatment of cells with rSAG2A or rSAG2A ${ }^{\Delta 135}$ induced very distinct patterns of response in innate cells. While the intact protein induced almost undetectable levels of $\mathrm{NO}$ and IL-12p40, $\mathrm{rSAG}_{2} \mathrm{~A}^{\Delta 135}$ triggered proinflammatory responses in BMMs (Figure 4B) and BMDCs (Figure 4C).

It is well known that $T$. gondii possesses great strain variability, usually represented by the expression of distinct isoforms of membrane-bound and secreted proteins $[8,18,39]$. That altered expression may correspond to differences in virulence factors to human and murine hosts [40,41]. Phylogenetic analysis of the protein sequence, using ToxoDB database, revealed that SAG2A protein sequences expressed in the major clonal $T$. gondii strains (I, II and III) present high identity. However, as previously described $[40,42]$, type II strains display a single additional glycine at position 139, if compared with type I/III strains (Figure 5A). Observation of the predicted three-dimensional models suggests that the additional glycine in SAG2A from type II strains promotes significant changes in protein structure, creating a predicted coil along the $\mathrm{C}$-terminal end of the sequence (Figures 5B). That structural modification is located in the predicted B-cell epitope, but it does not alter its antigenic recognition by directed monoclonal antibody, as described previously [18].

In order to check whether these predicted structural modifications within the IUP domain would alter the protein ability to modulate innate cell activation, we opsonized SAG2A IUP domains in tachyzoites of RH and Me49 strains with A4D12 mAb. As shown in Figure 5C, pretreatment of $\mathrm{RH}$ tachyzoites with A4D12 $\mathrm{mAb}$ resulted in increased production of NO by infected BMMs stimulated with LPS and IFN- $\gamma$. However, mAb sharply reverted Me49-promoted downregulation of NO, while that effect was not so evident in treated $\mathrm{RH}$ tachyzoites. The same pattern of events was observed for IL-12p40 production by BMDCs, where Me49 parasites blocked with $\mathrm{A} 4 \mathrm{D} 12 \mathrm{mAb}$ were able to induce greater production of the cytokine, if compared to $\mathrm{RH}$ treated tachyzoites (Figure 5D). These observations indicate that the modulatory potential of SAG2A 
A

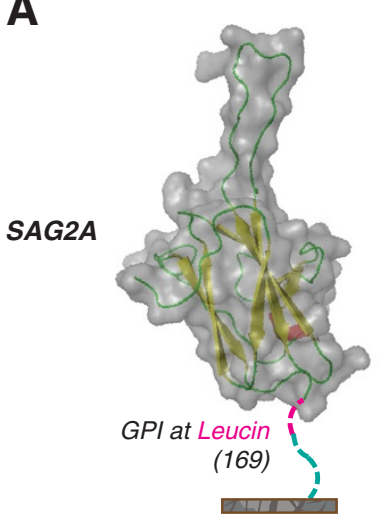

B
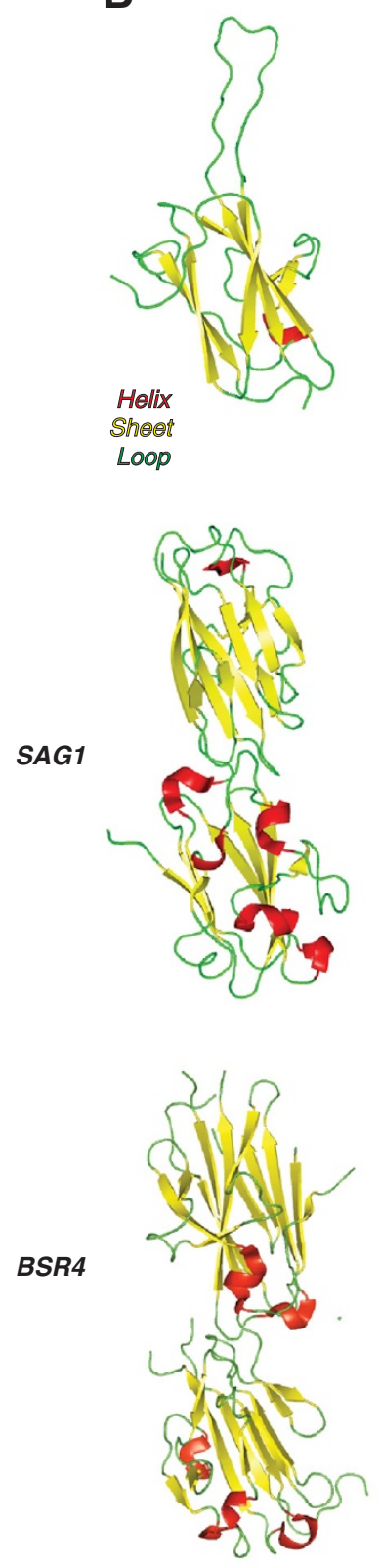

C

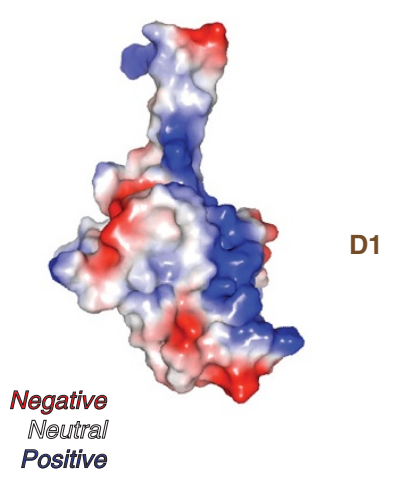

D1

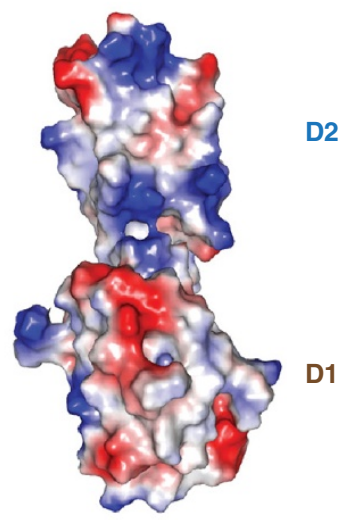

D2

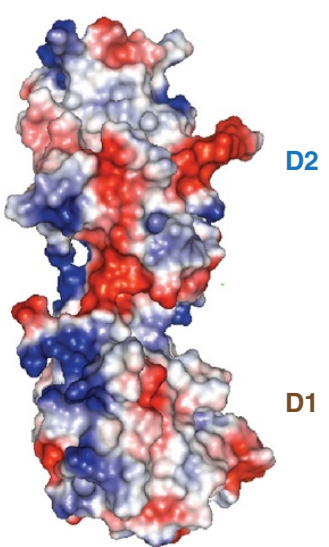

Figure 2 Anchorage site, carbon structure and charge distribution of SAG2A protein. (A) SAG2A anchorage in Toxoplasma gondii's surface surface by glycosyl-phosphatidylinositol (GPI) was predicted to be in a leucin at position 169 of its amino acid sequence, located at the Cterminal end of SAG2A. (B) The modeled carbon structure of SAG2A evidences a disordered amino acid sequence, absent in the SAG1 and BSR4 proteins. (C) The C-terminal end of SAG2A presents a relevant hydrophobic portion, with distinct polar amino acids at positions 134 and 137.

expressed in both parasite strains is distinct, which may be related to the differences displayed within its C-terminal domains.

\section{Discussion}

T. gondii surface antigens are crucial in the initial interactions with host cells, mediating events such as attachment and invasion [43,44]. Additionally, the ability of these proteins to induce cellular and serological immune responses has been in discussion since the early 1990's $[45,46]$.

Our results indicate, through structural modeling prediction, that SAG2A presents unique features in the C-terminal end of its amino acid sequence, which 


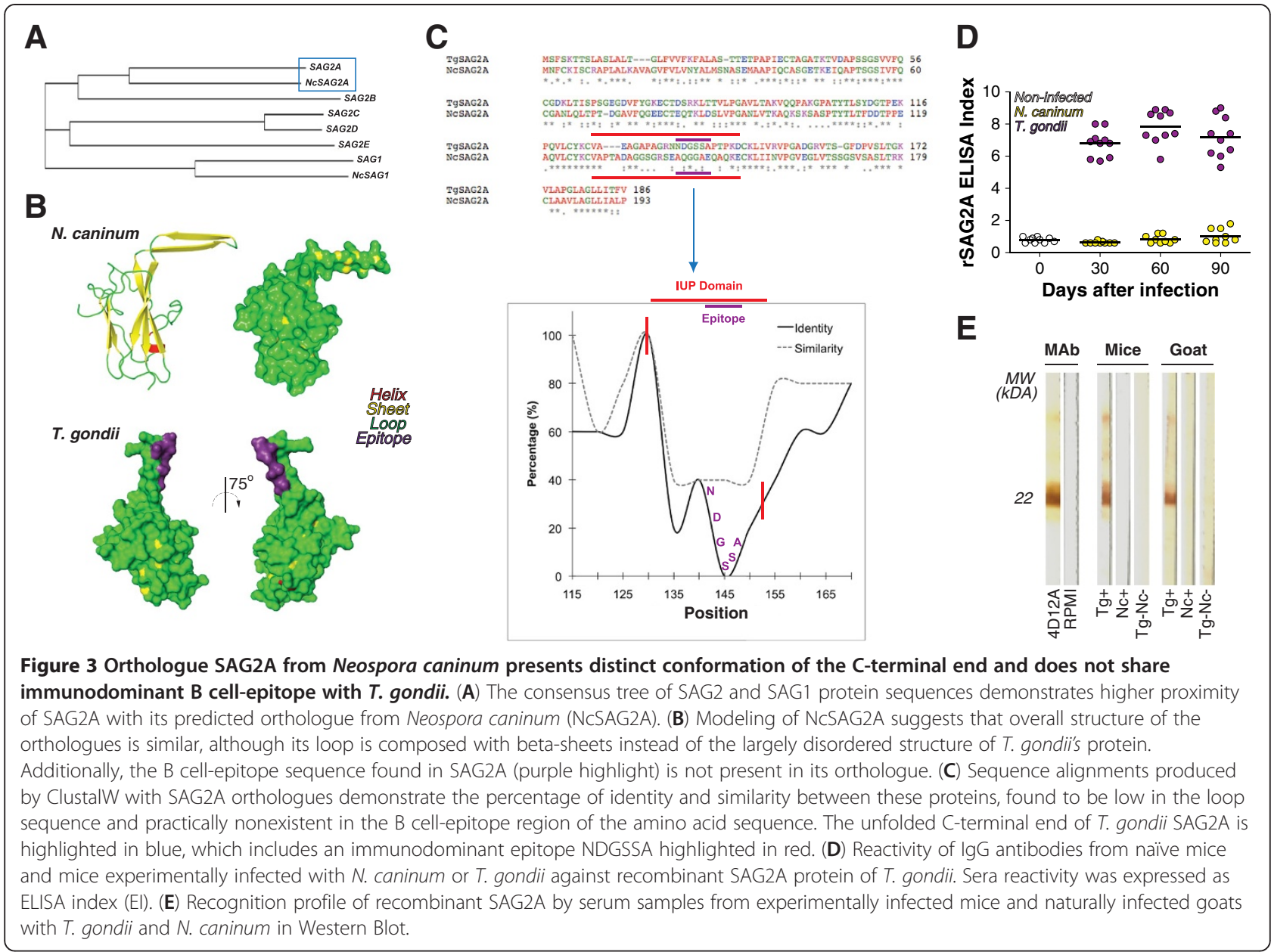

resembles the features of Intrinsically Unstructured Proteins (IUP). IUPs have been identified as probable causative elements of neurodegenerative diseases and viral virulence factors, due to their ability to interact with different molecules within the cells $[47,48]$. Previous studies have shown that some eukaryotic genomes present over $20 \%$ of residues with similar characteristics [49]. IUPs differ from structured proteins especially in their functions, usually related to catalysis, membrane transport and reversible binding of small molecules, signal transduction, cell-cycle regulation, gene expression and chaperone action [50-52]. The identification of proteins with disordered regions, and the mapping of their exact location within those molecules, can be an important step in the selection of antigenic targets due to their importance in microbial metabolism [49]. Genomic predictions have estimated that Apicomplexan parasites present IUP domains in a higher frequency than bacteria and archaea, and T. gondii is one of the parasites with most occurrences, alongside $P$. falciparum, $P$. vivax and P. knowlesi [53].

Our present work locates a previously predicted B cell linear epitope [18] within this predicted IUP domain of
SAG2A, which corroborates with our previous studies on immunodominance of the protein and its potential as an acute phase marker for the diagnosis of human toxoplasmosis $[32,33,54]$. In addition, we show here that recombinant SAG2A was able to specifically detect $T$. gondii-induced antibodies in experimental and natural infections eliminating potential serological cross-reactivity with closely related $N$. caninum, a long-lived setback within the veterinary field [55-57]. In a similar manner, other authors have confirmed that SAG2A protein can be used for diagnostic procedures, and also include this protein as a target in the development of subunit vaccines against T. gondii infection [58]. However, strategies involving SAG2A as an immunogen yield divergent results, and some failed to protect susceptible mice from lethal infections [59-61]. Based on our results, we believe that the inability to establish SAG2A as an immunogen in those studies may be due to the modulatory properties of its C-terminal end and we suggest that $\mathrm{rSAG} 2 A^{\Delta 135}$ should be tested in those experimental models.

Down regulation of innate immune response induced by parasite antigens, endogenous ligands or other microbial 


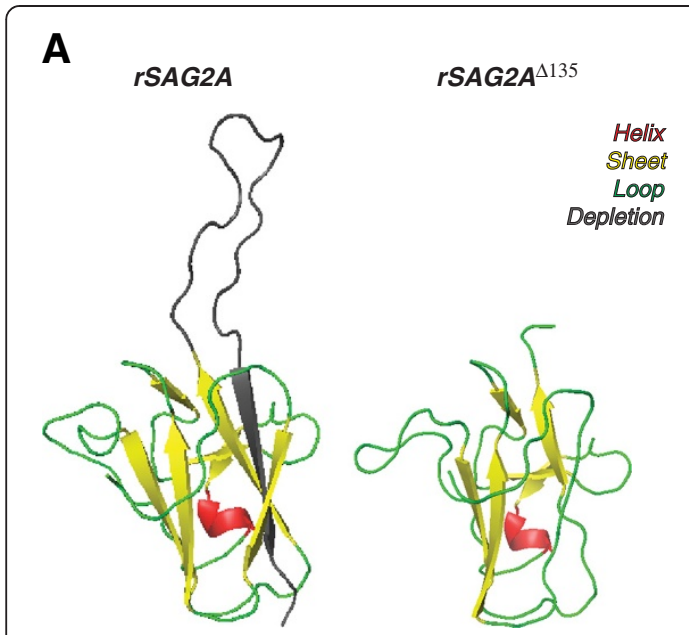

B

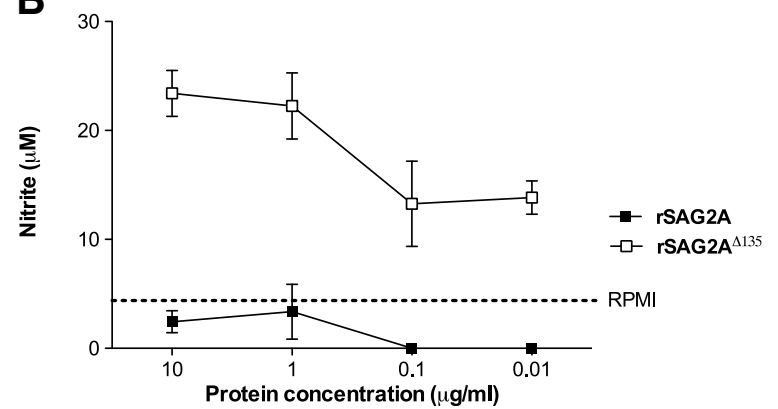

C

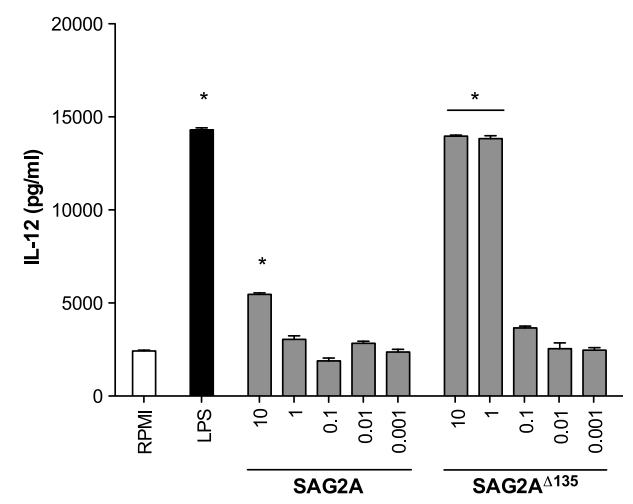

Figure 4 C-terminal end of SAG2A protein interacts with innate immune response. (A) Three-dimensional model of recombinant SAG2A (rSAG2A) and the truncated form of the protein ( $\left.r S A G 2 A^{\Delta 135}\right)$. Structural analysis shows that depletion of the C-terminal end did not affect the overall predicted three-dimensional structure or distribution of positive and negative charges along the protein. (B) Bone marrow-derived macrophages (BMMs) and (C) dendritic cells (BMDCs) were treated with different concentrations of rSAG2A and rSAG $2 A^{\Delta 135}$ for 48 and $24 \mathrm{~h}$, prior to determination of nitrite (B) and IL-12p40 levels (C), respectively. As controls, cells were left untreated (RPMI) or exposed to LPS $(1 \mu \mathrm{g} / \mathrm{ml})$ in similar time spam. Results are presented as mean \pm SEM. Dashed lines indicate mean values obtained for untreated BMMs. * Statistical significance $(p<0.05)$ in relation to untreated controls. molecules has been extensively assessed through the last decades $[62,63]$, although a very small number of parasitic proteins and their mechanisms of action have been identified with those properties. The results of this study suggest that the unusual C-terminal end predicted in SAG2A may directly affect the activation status of macrophages and dendritic cells. The absence of this C-terminal end in SAG2A, observed through antibody inhibition and depleted recombinant proteins, reverted the parasite-induced suppression of nitric oxide and IL-12p40 production by LPS - an experimental model based on studies that demonstrate the potent suppression of LPS-induced activation by $T$. gondii in cells of the immune system [35].

Parasite strategies to fine-tune the immune response of the host may be explained by its necessity to maintain the host alive during the acute phase of infection, in order to propagate and convert to latent stages inside muscular and nervous tissues, waiting for the infected host to be preyed upon by a carnivorous feline definitive host $[39,64,65]$. In this sense, with an interest in understanding the elaboration of the immune response through interaction between host and parasite, significant efforts have been placed on identifying parasite-derived ligands that may activate or deactivate immune responses triggered by the infection process $[5,6,16,66]$. Activation of innate immunity by $T$. gondii is mainly triggered by the Toll-like and chemokine receptor agonists $[1,67]$. Recent studies have demonstrated that TLR11/TLR12 activation via parasite actin-related profilin induces high production of IL-12p40 and IFN- $\gamma$, key cytokines required for host protection during toxoplasmosis [68,69], although innate pathogen sensing through this activation pathway is not preserved in all animal species [70].

Despite of its evolutionary need for host survival and maintenance of its epidemiological chain, T. gondii possesses a great variety of mechanisms to suppress pro-inflammatory responses, in order to evade the microbicidal mechanisms induced by molecules, such as NO, GTPase and inflammatory cytokines, which can be highly effective in parasite clearance [37,71,72]. A set of polymorphic kinases from $T$. gondii have recently been identified as virulence factors - namely ROP5, ROP16 and ROP18 - secreted from its rhoptries into the host cell cytoplasm [21,73]. Much attention has been given to ROP16, since it activates directly STAT3 and STAT6 in the host cell cytoplasm, inhibiting the production of proinflammatory mediators $[64,73,74]$. The control of proinflammatory cytokine production is in great part promoted by the IL-10/STAT3 signaling cascade during T. gondii infection [62]. As one might expect, the activation of this signaling pathway minimizes host cell damage, however, it prevents effective parasite clearance. Although the rhoptry kinases present great 


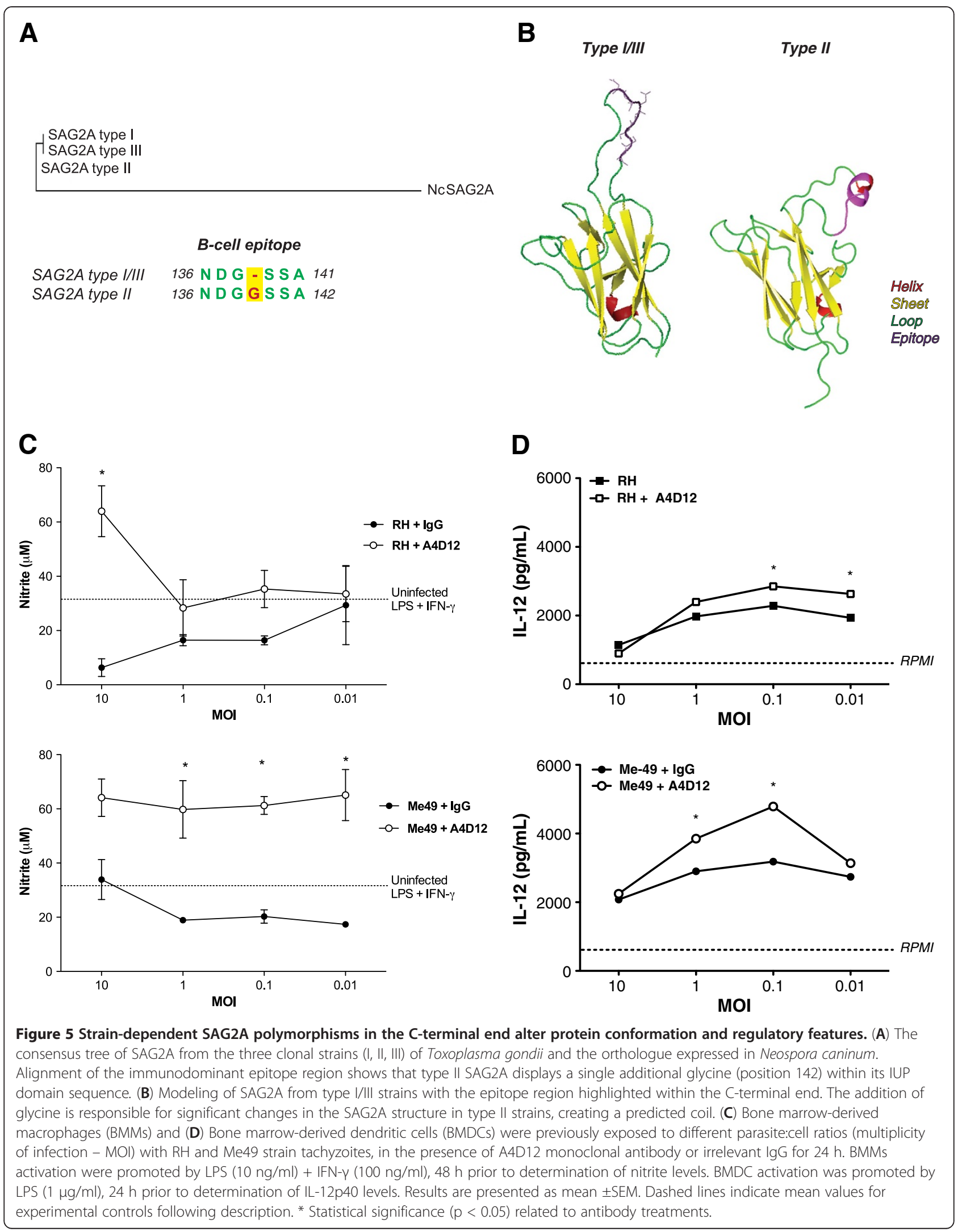


modulatory potential, it is not possible to affirm that these proteins are solely responsible for the evasion mechanisms displayed by the parasite, since some contradictions have been reported in different models of analysis [64].

We have also observed that antibody inhibition of SAG2A in T. gondii strains induced differential immune response profiles in innate cells. Genetic distinctions found between $T$. gondii strains have been implicated in the pathogenesis of the disease, through host immune cell modulation $[41,75]$. Disparity between $T$. gondii strains commonly occurs due to amino acid polymorphisms, rather than quantitative differences. It has been shown that ROP16 presents a single amino acid substitution in the kinase domain between type I and type II strains, which is sufficient for differential STAT3 activation [76]. Another example described recently are the polymorphisms within strains in the GRA15 locus that interferes directly with NF- $\mathrm{B}$ activation in the host cell, leading to differential immunopathology in the mouse model $[77,78]$. Understanding the role of each of these proteins may be an important step to unravel the host-parasite interactions during toxoplasmosis. Polymorphisms at the SAG2A locus are found to be between $1 \%$ and $5 \%$, and antibodies against the protein isolated after natural infections were shown to be strain-specific, even though all three strain types (I, II, III) express approximately equal levels of the SAG2A protein, suggesting that although polymorphic, epitopes within SAG2A are still highly immunogenic and immunodominant [40].

\section{Conclusions}

In conclusion, we found that the C-terminal end of $T$. gondii surface protein SAG2A interacts with distinct immune mechanisms, sheltering a known B cell epitope, also being potentially involved with immune evasion of macrophages and dendritic cells. In this context, further studies are needed in order to confirm the exact intracellular mechanisms activated by its $\mathrm{C}$-terminal end. The confirmation of these results could provide relevant information for the development of new prophylactic and therapeutic approaches toward toxoplasmosis.

\section{Competing interests}

There are no potential competing interests related to the data herein presented.

\section{Authors' contributions}

Conceived and designed the experiments: AGMJr JPCJr CPP DAOS JRM TWPM. Performed the experiments: AGMJr THSC MVS FMS DAOS TWPM. Analyzed the data: AGMJr JPCJr THSC FMS CPP DAOS JRM TWPM. Wrote the paper: AGMJr JPCJr TWPM. All authors read and approved the final version of the manuscript.

\section{Acknowledgments}

The authors thank Marley Dantas Barbosa and Zilda Mendonça da Silva Rodrigues for technical assistance. This work was supported by Brazilian funding agencies CNPq, CAPES and FAPEMIG.

\section{Author details}

'Laboratório de Imunoparasitologia "Dr. Mário Endsfeldz Camargo", Instituto de Ciências Biomédicas, Universidade Federal de Uberlândia, Av. Pará 1720 Bloco 4C, Campus Umuarama, Uberlândia, Minas Gerais 38.400-902, Brazil. ${ }^{2}$ Centro de Biotecnologia e Genética, Universidade Estadual de Santa Cruz, Rodovia Ilhéus/Itabuna km 16, Ilhéus, Bahia 45.662-900, Brazil. ${ }^{3}$ Laboratório de Imunoparasitologia, Faculdade de Medicina de Ribeirão Preto, Universidade de São Paulo, Av. Bandeirantes, 3900, Ribeirão Preto, São Paulo 14.015-000, Brazil.

Received: 20 April 2013 Accepted: 26 May 2013

Published: 5 June 2013

\section{References}

1. Blader IJ, Saeij JP: Communication between Toxoplasma gondii and its host: impact on parasite growth, development, immune evasion, and virulence. APMIS 2009, 117:458-476.

2. Weiss LM, Dubey JP: Toxoplasmosis: A history of clinical observations. Int J Parasitol 2009, 39:895-901.

3. Tenter AM, Heckeroth AR, Weiss LM: Toxoplasma gondii: from animals to humans. Int J Parasitol 2000, 30:1217-1258.

4. Montoya JG, Rosso F: Diagnosis and management of toxoplasmosis. Clin Perinatol 2005, 32:705-726.

5. Reese ML, Boothroyd JC: A helical membrane-binding domain targets the Toxoplasma ROP2 family to the parasitophorous vacuole. Traffic 2009, 10:1458-1470

6. Gong H, Kobayashi K, Sugi T, Takemae H, Kurokawa H, Horimoto T, Akashi $H$, Kato K: A Novel PAN/Apple Domain-Containing Protein from Toxoplasma gondii: Characterization and Receptor Identification. PLoS One 2012, 7:e30169.

7. Ong YC, Boyle JP, Boothroyd JC: Strain-dependent host transcriptional responses to Toxoplasma infection are largely conserved in mammalian and avian hosts. PLoS One 2011, 6:e26369.

8. Lekutis C, Ferguson DJ, Grigg ME, Camps M, Boothroyd JC: Surface antigens of Toxoplasma gondii: variations on a theme. Int J Parasitol 2001, 31:1285-1292.

9. Che FY, Madrid-Aliste C, Burd B, Zhang H, Nieves E, Kim K, Fiser A, Angeletti $\mathrm{RH}$, Weiss LM: Comprehensive proteomic analysis of membrane proteins in Toxoplasma gondii. Mol Cell Proteomics 2011, 10:M110.000745.

10. Fauquenoy S, Hovasse A, Sloves PJ, Morelle W, Dilezitoko Alayi T, Slomianny C, Werkmeister E, Schaeffer C, Van Dorsselaer A, Tomavo S: Unusual $\mathrm{N}$-glycan structures required for trafficking Toxoplasma gondii GAP50 to the inner membrane complex regulate host cell entry through parasite motility. Mol Cell Proteomics 2011, 10:M111.008953.

11. Fritz HM, Bowyer PW, Bogyo M, Conrad PA, Boothroyd JC: Proteomic analysis of fractionated Toxoplasma oocysts reveals clues to their environmental resistance. PLoS One 2012, 7:e29955.

12. Hajagos BE, Turetzky JM, Peng ED, Cheng SJ, Ryan CM, Souda P, Whitelegge JP, Lebrun M, Dubremetz JF, Bradley PJ: Molecular dissection of novel trafficking and processing of the Toxoplasma gondii rhoptry metalloprotease toxolysin-1. Traffic 2012, 13:292-304.

13. Bai Y, He S, Zhao G, Chen L, Shi N, Zhou H, Cong H, Zhao Q, Zhu XQ: Toxoplasma gondii: Bioinformatics analysis, cloning and expression of a novel protein TgIMP1. Exp Parasitol 2012, 132:458-464

14. Crawford J, Tonkin ML, Grujic O, Boulanger MJ: Structural characterization of apical membrane antigen 1 (AMA1) from Toxoplasma gondii. J Biol Chem 2010, 285:15644-15652.

15. Saouros S, Dou Z, Henry M, Marchant J, Carruthers VB, Matthews S: Microneme protein 5 regulates the activity of Toxoplasma subtilisin 1 by mimicking a subtilisin prodomain. J Biol Chem 2012, 287:36029-36040.

16. Tonkin $M L$, Roques $M$, Lamarque $M H$, Pugnière $M$, Douguet $D$, Crawford J, Lebrun M, Boulanger MJ: Host cell invasion by apicomplexan parasites: insigts from the co-structure of AMA1 with RON2 peptide. Science 2011, 333:463-467.

17. Lekutis C, Ferguson DJ, Boothroyd JC: Toxoplasma gondii: identification of a developmentally regulated family of genes related to SAG2. Exp Parasitol 2000, 96:89-96.

18. Cunha-Júnior JP, Silva DA, Silva NM, Souza MA, Souza GR, Prudencio CR, Pirovani CP, Cezar M, Cascardo J, Barbosa BF, Goulart LR, Mineo JR: A4D12 monoclonal antibody recognizes a new linear epitope from SAG2A Toxoplasma gondii tachyzoites, identified by phage display bioselection. Immunobiology 2010, 215:26-37. 
19. Fux B, Rodrigues CV, Portela RW, Silva NM, Su C, Sibley D, Vitor RW, Gazzinelli RT: Role of cytokines and major histocompatibility complex restriction in mouse resistance to infection with a natural recombinant strain (type I-III) of Toxoplasma gondii. Infect Immun 2003, 71:6392-6401.

20. Liu S, Tobias R, McClure S, Styba G, Shi Q, Jackowski G: Removal of endotoxin from recombinant protein preparations. Clin Biochem 1997 30:455-463

21. Behnke MS, Khan A, Wootton JC, Dubey JP, Tang K, Sibley LD: Virulence differences in Toxoplasma mediated by amplification of a family of polymorphic pseudokinases. Proc Natl Acad Sci USA 2011, 108:9631-9636.

22. Henikoff $S$, Henikoff JG: Amino acid substitution matrices from protein blocks. Proc Natl Acad Sci USA 1992, 89:10915-10919.

23. He XL, Grigg ME, Boothroyd JC, Garcia KC: Structure of the immunodominant surface antigen from the Toxoplasma gondii SRS superfamily. Nat Struct Biol 2002, 9:606-611.

24. Crawford J, Grujic O, Bruic E, Czjzek M, Grigg ME, Boulanger MJ: Structural characterization of the bradyzoite surface antigen (BSR4) from Toxoplasma gondii, a unique addition to the surface antigen glycoprotein 1-related superfamily. J Biol Chem 2009, 284:9192-9198.

25. Laskowski RA, Rullmannn JA, MacArthur MW, Kaptein R, Thornton JM: AQUA and PROCHECK-NMR: programs for checking the quality of protein structures solved by NMR. J Biomol NMR 1996, 8:477-486.

26. Melo F, Devos D, Depiereux E, Feytmans E: ANOLEA: a www server to assess protein structures. Proc Int Conf Intell Syst Mol Biol 1997, 5:187-190.

27. Melo F, Feytmans E: Assessing protein structures with a non-local atomic interaction energy. J Mol Biol 1998, 277:1141-1152.

28. Ramachandran GN, Ramakrishnan C, Sasisekharan V: Stereochemistry of polypeptide chain configurations. J Mol Biol 1963, 7:95-99.

29. Marim FM, Silveira TN, Lima DS Jr, Zamboni DS: A method for generation of bone marrow-derived macrophages from cryopreserved mouse bone marrow cells. PLoS One 2010, 5:e15263.

30. Mineo TW, Oliveira CJ, Gutierrez FR, Silva JS: Recognition by Toll-like receptor 2 induces antigen-presenting cell activation and Th1 programming during infection by Neospora caninum. Immunol Cell Biol 2010, 88:825-833.

31. Sherman MP, Aeberhard EE, Wong VZ, Griscavage JM, Ignarro LJ: Pyrrolidine dithiocarbamate inhibits induction of nitric oxide synthase activity in rat alveolar macrophages. Biochem Biophys Res Commun 1993, 191:1301-1308.

32. Béla SR, Oliveira Silva DA, Cunha-Júnior JP, Pirovani CP, Chaves-Borges FA, Reis de Carvalho F, Carrijo de Oliveira T, Mineo JR: Use of SAG2A recombinant Toxoplasma gondii surface antigen as a diagnostic marker for human acute toxoplasmosis: analysis of titers and avidity of IgG and IgG1 antibodies. Diagn Microbiol Infect Dis 2008, 62:245-254.

33. Santana SS, Silva DA, Vaz LD, Pirovani CP, Barros GB, Lemos EM, Dietze R, Mineo JR, Cunha-Junior JP: Analysis of IgG subclasses (IgG1 and IgG3) to recombinant SAG2A protein from Toxoplasma gondii in sequential serum samples from patients with toxoplasmosis. Immunol Lett 2012, 143:193-201.

34. Silva DA, Silva NM, Mineo TW, Pajuaba Neto AA, Ferro EA, Mineo JR: Heterologous antibodies to evaluate the kinetics of the humoral immune response in dogs experimentally infected with Toxoplasma gondii RH strain. Vet Parasitol 2002, 107:181-195.

35. Moreno B, Collantes-Fernández E, Villa A, Navarro A, Regidor-Cerrillo J, OrtegaMora LM: Occurrence of Neospora caninum and Toxoplasma gondii infections in ovine and caprine abortions. Vet Parasito/ 2012, 187:312-318.

36. Leng J, Butcher BA, Denkers EY: Dysregulation of macrophage signal transduction by Toxoplasma gondii: past progress and recent advances. Parasite Immunol 2009, 31:717-728.

37. Buzoni-Gatel D, Werts C: Toxoplasma gondii and subversion of the immune system. Trends Parasitol 2006, 22:448-452

38. Leng J, Butcher BA, Egan CE, Abdallah DS, Denkers EY: Toxoplasma gondi prevents chromatin remodeling initiated by TLR-triggered macrophage activation. J Immunol 2009, 182:489-497.

39. Boothroyd JC: Toxoplasma gondii: 25 years and 25 major advances for the field. Int J Parasitol 2009, 39:935-946.

40. Kong JT, Grigg ME, Uyetake L, Parmley S, Boothroyd JC: Serotyping of Toxoplasma gondii infections in humans using synthetic peptides. J Infect Dis 2003, 187:1484-1495

41. Taylor S, Barragan A, Su C, Fux B, Fentress SJ, Tang K, Beatty WL, Haij HE, Jerome M, Behnke MS, White M, Wootton JC, Sibley LD: A secreted serine-threonine kinase determines virulence in the eukaryotic pathogen Toxoplasma gondii. science 2006, 314:1776-1780.
42. Parmley SF, Gross U, Sucharczuk A, Windeck T, Sgarlato GD, Remington JS: Two alleles of the gene encoding surface antigen P22 in 25 strains of Toxoplasma gondii. J Parasitol 1994, 80:293-301.

43. Jung C, Lee CY, Grigg ME: The SRS superfamily of Toxoplasma surface proteins. Int J Parasitol 2004, 34:285-296.

44. Velge-Roussel F, Dimier-Poisson I, Buzoni-Gatel D, Bout D: Anti-SAG1 peptide antibodies inhibit the penetration of Toxoplasma gondii tachyzoites into enterocyte cell lines. Parasitology 2001, 123:225-233.

45. Mineo JR, McLeod R, Mack D, Smith J, Khan IA, Ely KH, Kasper LH: Antibodies to Toxoplasma gondii major surface protein (SAG-1, P30) inhibit infection of host cells and are produced in murine intestine after peroral infection. J Immunol 1993, 150:3951-3964.

46. Gazzinelli RT, Eltoum I, Wynn TA, Sher A: Acute cerebral toxoplasmosis is induced by in vivo neutralization of TNF-alpha and correlates with the down-regulated expression of inducible nitric oxide synthase and other markers of macrophage activation. J Immunol 1993, 151:3672-3681.

47. Das S, Mukhopadhyay D: Intrinsically unstructured proteins and neurodegenerative diseases: conformational promiscuity at its best. IUBMB Life 2011, 63:478-488.

48. Ivanyi-Nagy $R$, Darlix JL: Intrinsic disorder in the core proteins of flaviviruses. Protein Pept Lett 2010, 17:1019-1025

49. Dosztanyi Z, Csizmok V, Tompa P, Simon I: The pairwise energy content estimated from amino acid composition discriminates between folded and intrinsically unstructured proteins. J Mol Biol 2005, 347:827-839.

50. Chen K, Kurgan LA, Ruan J: Prediction of flexible/rigid regions from protein sequences using k-spaced amino acid pairs. BMC Struct Biol 2007, 7:25.

51. Tompa P, Szasz C, Buday L: Structural disorder throws new light on moonlighting. Trends Biochem Sci 2005, 30:484-489.

52. Tompa $P$ : The interplay between structure and function in intrinsically unstructured proteins. FEBS Lett 2005, 579:3346-3354.

53. Feng ZP, Zhang X, Han P, Arora N, Anders RF, Norton RS: Abundance of intrinsically unstructured proteins in $P$. falciparum and other apicomplexan parasite proteomes. Mol Biochem Parasitol 2006, 150:256-267.

54. Carvalho FR, Silva DA, Cunha-Júnior JP, Souza MA, Oliveira TC, Béla SR, Faria GG, Lopes CS, Mineo JR: Reverse enzyme-linked immunosorbent assay using monoclonal antibodies against SAG1-related sequence, SAG2A, and p97 antigens from Toxoplasma gondii to detect specific immunoglobulin $\mathrm{G}(\mathrm{lgG})$, $\lg \mathrm{M}$, and $\lg \mathrm{A}$ antibodies in human sera. Clin Vaccine Immunol 2008, 15:1265-1271.

55. Björkman C, Uggla A: Serological diagnosis of Neospora caninum infection. Int J Parasitol 1999, 29:1497-1507.

56. Staubli D, Nunez S, Sager H, Schares G, Gottstein B: Neospora caninum immunoblotting improves serodiagnosis of bovine neosporosis. Parasitol Res 2006, 99:648-658.

57. Silva DA, Lobato J, Mineo TW, Mineo JR: Evaluation of serological tests for the diagnosis of Neospora caninum infection in dogs: optimization of cut off titers and inhibition studies of cross-reactivity with Toxoplasma gondii. Vet Parasitol 2007, 143:234-244.

58. Yan H, Yan H, Tao Y, Chen H, Li G, Gong W, Jiao H, Tian F, Ji M: Application and expression of Toxoplasma gondii surface antigen 2 (SAG2) and rhoptry protein 2 (ROP2) from recombinant Escherichia coli strain. Trans $R$ Soc Trop Med Hyg 2012, 106:356-362.

59. Mishima M, Xuan X, Shioda A, Omata Y, Fujisaki K, Nagasawa H, Mikami T: Modified protection against Toxoplasma gondii lethal infection and brain cyst formation by vaccination with SAG2 and SRS1. J Vet Med Sci 2001, 63:433-438

60. Machado AV, Caetano BC, Barbosa RP, Salgado AP, Rabelo RH, Garcia CC, Bruna-Romero O, Escriou N, Gazzinelli RT: Prime and boost immunization with influenza and adenovirus encoding the Toxoplasma gondii surface antigen 2 (SAG2) induces strong protective immunity. Vaccine 2010 28:3247-3256

61. Mendes EA, Caetano BC, Penido ML, Bruna-Romero O, Gazzinelli RT: MyD88dependent protective immunity elicited by adenovirus 5 expressing the surface antigen 1 from Toxoplasma gondii is mediated by CD8(+) T lymphocytes. Vaccine 2011, 29:4476-4484.

62. Miller CM, Boulter NR, Ikin RJ, Smith NC: The immunobiology of the innate response to Toxoplasma gondii. Int J Parasitol 2009, 39:23-39.

63. Pollard AM, Knoll LJ, Mordue DG: The role of specific Toxoplasma gondii molecules in manipulation of innate immunity. Trends Parasitol 2009, 25:491-494 
64. Butcher BA, Fox BA, Rommereim LM, Kim SG, Maurer KJ, Yarovinsky F, Herbert DR, Bzik DJ, Denkers EY: Toxoplasma gondii rhoptry kinase ROP16 activates STAT3 and STAT6 resulting in cytokine inhibition and arginase1-dependent growth control. PLoS Pathog 2011, 7:e1002236.

65. Sacks D, Sher A: Evasion of innate immunity by parasitic protozoa. Nat Immunol 2002, 3:1041-1047.

66. Niedelman W, Gold DA, Rosowski EE, Sprokholt JK, Lim D, Farid Arenas A, Melo MB, Spooner E, Yaffe MB, Saeij JP: The rhoptry proteins ROP18 and ROP5 mediate Toxoplasma gondii evasion of the murine, but not the human, interferon-gamma response. PLoS Pathog 2012, 8:e1002784.

67. Aliberti J, Reis e Sousa C, Schito M, Hieny S, Wells T, Huffnagle GB, Sher A: CCR5 provides a signal for microbial induced production of IL-12P40 by CD8 alpha+ dendritic cells. Nat Immunol 2000, 1:83-87.

68. Yarovinsky F, Zhang D, Andersen JF, Bannenberg GL, Serhan CN, Hayden MS, Hieny S, Sutterwala FS, Flavell RA, Ghosh S, Sher A: TLR11 activation of dendritic cells by a protozoan profilin-like protein. Science 2005, 308:1626-1629.

69. Koblansky AA, Jankovic D, Oh H, Hieny S, Sungnak W, Mathur R, Hayden MS, Akira S, Sher A, Ghosh S: Recognition of Profilin by Toll-like Receptor 12 is Critical for Host Resistance to Toxoplasma gondii. Immunity 2013, 38:119-130.

70. Andrade WA, Souza Mdo C, Ramos-Martinez E, Nagpal K, Dutra MS, Melo MB, Bartholomeu DC, Ghosh S, Golenbock DT, Gazzinelli RT: Combined Action of Nucleic Acid-Sensing Toll-like Receptors and TLR11/TLR12 Heterodimers Imparts Resistance to Toxoplasma gondii in Mice. Cell Host Microbe 2013, 13:42-53.

71. Plattner F, Soldati-Favre D: Hijacking of host cellular functions by the Apicomplexa. Annu Rev Microbiol 2008, 62:471-487.

72. Lambert $\mathrm{H}$, Barragan A: Modelling parasite dissemination: host cell subversion and immune evasion by Toxoplasma gondii. Cell Microbiol 2010, 12:292-300.

73. Saeij JP, Coller S, Boyle JP, Jerome ME, White MW, Boothroyd JC Toxoplasma co-opts host gene expression by injection of a polymorphic kinase homologue. Nature 2007, 445:324-327.

74. Ong YC, Reese ML, Boothroyd JC: Toxoplasma rhoptry protein 16 (ROP16) subverts host function by direct tyrosine phosphorylation of STAT6. J Biol Chem 2010, 285:28731-28740.

75. Saeij JP, Boyle JP, Boothroyd JC: Differences among the three major strains of Toxoplasma gondii and their specific interactions with the infected host. Trends Parasitol 2005, 21:476-481.

76. Yamamoto M, Standley DM, Takashima S, Saiga H, Okuyama M, Kayama H, Kubo E, Ito H, Takaura M, Matsuda T, Soldati-Favre D, Takeda K: A single polymorphic amino acid on Toxoplasma gondii kinase ROP16 determines the direct and strain-specific activation of Stat3. J Exp Med 2009, 206:2747-2760.

77. Jensen KD, Wang Y, Wojno ED, Shastri AJ, Hu K, Cornel L, Boedec E, Ong YC, Chien YH, Hunter CA, Boothroyd JC, Saeij JP: Toxoplasma polymorphic effectors determine macrophage polarization and intestinal inflammation. Cell Host Microbe 2011, 9:472-483.

78. Rosowski EE, Lu D, Julien L, Rodda L, Gaiser RA, Jensen KD, Saeij JP: Strainspecific activation of the NF-kappaB pathway by GRA15, a novel Toxoplasma gondii dense granule protein. J Exp Med 2011, 208:195-212.

doi:10.1186/1756-3305-6-163

Cite this article as: Macêdo et al: SAG2A protein from Toxoplasma gondii interacts with both innate and adaptive immune compartments of infected hosts. Parasites \& Vectors 2013 6:163.

\section{Submit your next manuscript to BioMed Central and take full advantage of:}

- Convenient online submission

- Thorough peer review

- No space constraints or color figure charges

- Immediate publication on acceptance

- Inclusion in PubMed, CAS, Scopus and Google Scholar

- Research which is freely available for redistribution 